Article

\title{
Coseismic Slip Distribution of the 2019 Mw 7.5 New Ireland Earthquake from the Integration of Multiple Remote Sensing Techniques
}

\author{
Chuang Song ${ }^{1}$, Chen $\mathrm{Yu}^{1, * \mathbb{D}}$, Zhenhong $\mathrm{Li}^{1,2}$, Yongsheng $\mathrm{Li}^{1,3}$ and Ruya Xiao ${ }^{1,4}$ \\ 1 School of Engineering, Newcastle University, Newcastle upon Tyne NE1 7RU, UK; \\ c.song4@newcastle.ac.uk (C.S.); zhenhong.li@newcastle.ac.uk (Z.L.) yongsheng.li@ncl.ac.uk (Y.L.); \\ ruya.xiao@hhu.edu.cn (R.X.) \\ 2 College of Geological Engineering and Geomatics, Chang'an University, Xi'an 710054, China \\ 3 Institute of Crustal Dynamics, China Earthquake Administration, Beijing 100086, China \\ 4 School of Earth Science and Engineering, Hohai University, Nanjing 211100, China \\ * Correspondence: chen.yu@newcastle.ac.uk; Tel.: +44-7476032633
}

Received: 31 October 2019; Accepted: 22 November 2019; Published: 24 November 2019

\begin{abstract}
The 2019 Mw 7.5 New Ireland earthquake occurred at an equatorial area where the dense vegetation prevents remote sensing techniques such as $\mathrm{C}$ - or $\mathrm{X}$-band interferometric synthetic aperture radar (SAR) from acquiring coherent phase measurements. Therefore, in this paper, multiple remote sensing techniques including the L-band interferometric SAR, the range and azimuth offset tracking of SAR intensities, and the offset tracking of optical images were employed to map its co-seismic deformation field and to determine the slip distribution. The surface rupture was clearly and consistently captured by all offset observations, with the ground fault trace striking at an angel of $315^{\circ}$ and extending over $10 \mathrm{~km}$. An iterative weighting strategy based on the residual root mean square of inversions using individual datasets was developed to determine the relative weight of each dataset, allowing for the joint inversion of the fault geometry, the refinement of the dip angle, and the determination of the best fitting slip distribution. The resultant model indicates a nearly left-lateral strike-slip motion on the Weitin fault that ruptured to the surface with a maximum slip of $6.10 \mathrm{~m}$, occurring at a depth of $\sim 10 \mathrm{~km}$, and a geodetic moment release of $1.03 \times 1020 \mathrm{Nm}$, corresponding to a magnitude of Mw 7.31. The distribution of aftershocks shows about $70 \%$ of aftershocks were located in the area with increased Coulomb failure stress and few aftershocks in the subduction zone to the south of the Weitin fault were triggered by this event.
\end{abstract}

Keywords: New Ireland earthquake; radar interferometry; image offset; strike-slip; joint inversion

\section{Introduction}

On 14 May 2019 (UTC 12:58:25), an Mw 7.5 earthquake occurred in New Ireland, eastern Papua New Guinea (Figure 1). It ruptured the Weitin fault, a strike-slip fault across the south of New Ireland, along the boundary between the South Bismarck and North Bismarck microplates. The epicentre initially estimated by the U.S. Geological Survey (USGS) was $4.081^{\circ} \mathrm{S}, 152.569^{\circ} \mathrm{E}$, with a focal depth of $\sim 10.0 \mathrm{~km}$, indicating a shallow strike-slip fault. The earthquake was followed by 43 aftershocks with a magnitude $>\mathrm{Mb} 4.0$ within five days of the main shock. Two moderate aftershocks on 14 May, both with a magnitude of $\mathrm{Mb} 5.0$, respectively occurred $\sim 40 \mathrm{~min}$ and $\sim 100 \mathrm{~min}$ after the main event and were located $\sim 18 \mathrm{~km}$ southeast and $\sim 70 \mathrm{~km}$ northwest of the main shock. However, the largest aftershock occurred on 17 May 2019 with a magnitude of Mb 5.9, located $74 \mathrm{~km}$ southeast of the main event. The earthquake catalogue from USGS show that the focal depth of the three aftershocks was $10.0,12.1$, and $21.0 \mathrm{~km}$, respectively. 


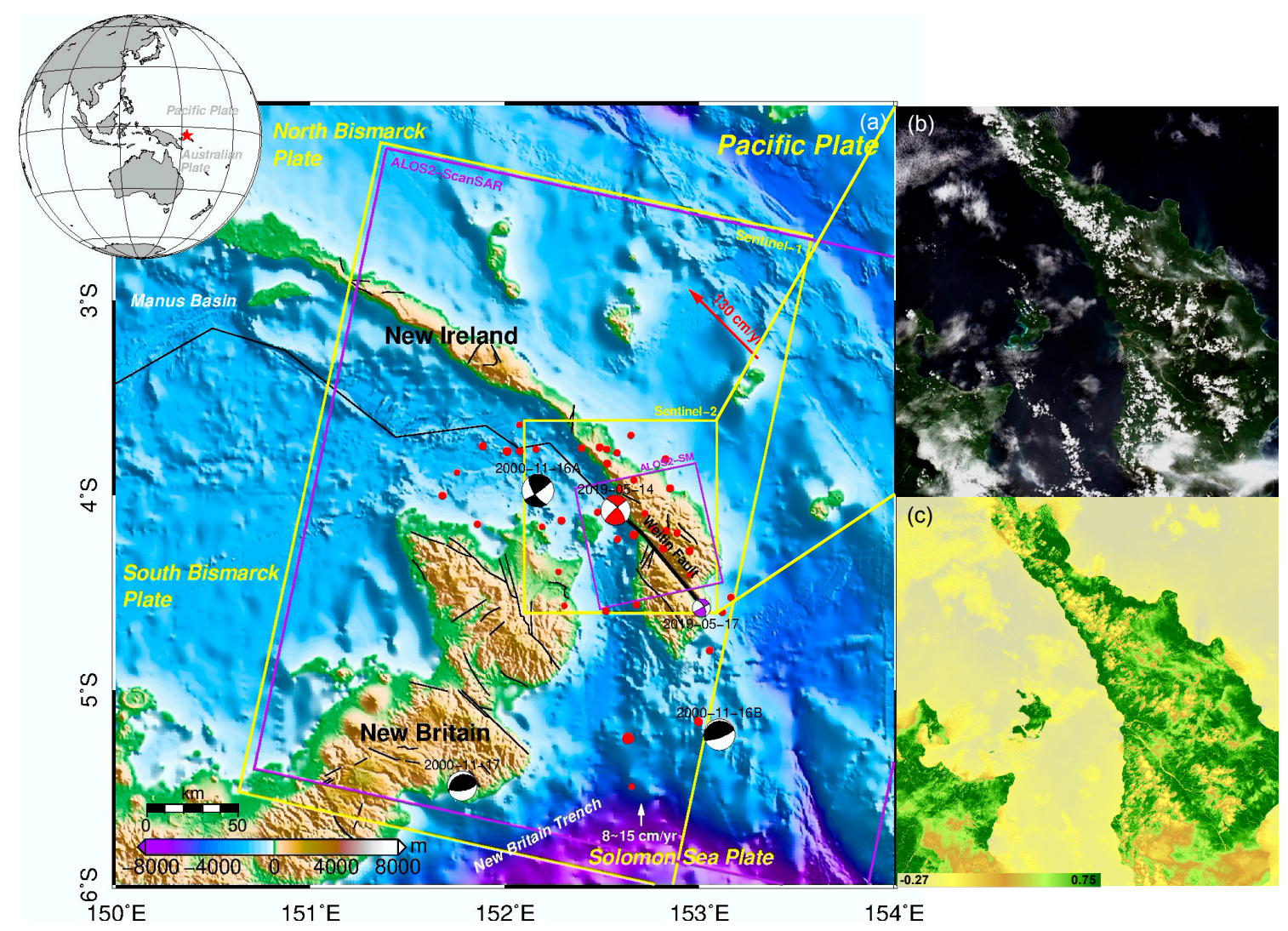

Figure 1. (a) Regional tectonic setting of the 2019 New Ireland earthquake. The in-panel global map reveals the relative location between New Ireland, the Pacific plate, and the Australian plate, where the red star denotes the location of this earthquake. The red beach ball represents the focal mechanism of the 2019 New Ireland earthquake from United States Geological Survey (USGS) while the purple one represents its largest aftershock. The red dots denote all other aftershocks five days after the main event recorded by the USGS. The black beach balls represent three large historical earthquakes in this region that occurred in November 2000. The solid black lines denote the major active faults in the region. The black line above the main shock is the offshore extension of the Weitin fault. The yellow rectangles outline the spatial coverage of the Sentinel-1 (descending track 16) and Sentinel-2 (track 116) frames. The purple rectangles outline the spatial coverage of ALOS-2 ScanSAR (descending track 6) and ALOS-2 strip map (track 108) frames. (b) Natural colour display of Sentinel-2 data imaged on 26 May 2019. (c) Normalized difference vegetation index (NDVI) map calculated from the near-infrared spectrum (band 8 ) and red range of the spectrum (band 4) of the Sentinel-2 image, where large values (from 0.6 to 0.8 ) indicate temperate or tropical forests.

Papua New Guinea, located in a complex tectonic setting between the Pacific plate and Australian plates (Figure 1a), is one of the most seismically active regions in the world. Several microplates in its centre and west including the Solomon Sea, South Bismarck, and North Bismarck microplates compose part of the edge of the Pacific and Australian plates [1,2]. As a transform boundary [3], more than 35 earthquakes with a magnitude greater than Mw 7 have occurred since 1970. These include a well-documented Mw 8.0 earthquake that occurred on 16 November 2000, $45 \mathrm{~km}$ to the northwest of the 14 May 2019 event, which was followed by two Mw 7.8 aftershocks on the subduction zone between the Solomon Sea and Pacific plates [4]. Tregoning et al. [5] used teleseismic data to relocate the aftershocks and concluded that the accumulated strain on the Weitin fault was fully released during the main shock because no aftershocks were located in the upper $15 \mathrm{~km}$ of the Weitin fault. Determining the coseismic slip distribution of the 16 November 2000 event constrained by the teleseismic wave data, Geist and Parsons [6] modelled the changes in the Coulomb failure stress, which they inferred had contributed to the first Mw 7.8 thrust aftershock. However, Park and Mori [7] carried out inversions 
using teleseismic $\mathrm{P}$ waveforms and showed that the static stress triggering mechanism hardly explains all of the triggered events in the earthquake sequence. To conclude, uncertainties exist due to limited observations for the investigation of the interaction of the faults in New Ireland and subduction trenches (e.g., New Britain trench), especially during large strike-slip earthquakes that occurred on the Weitin fault. Therefore, the 14 May 2019 event, covered for the first time by abundant geodetic observations with a high spatial resolution, provides a great opportunity to study the detailed fault behaviour and potential seismic hazard around New Ireland.

Interferometric synthetic aperture radar (InSAR) has been widely used for tectonic and volcanic studies since the early 1990s [8-10]. However, their phase measurements may significantly lose coherence in this heavy vegetation (as shown in Figure $1 b, c$ ) area, especially for sensors with short wavelengths such as X-and C-bands, limiting their usages in tropical regions. The decorrelation and unwrapping problems intensify for areas with large displacement gradient. It is therefore reasonable to employ multiple remote sensing observations that are feasible over vegetation-covered areas such as the L-band interferometric phase measurement (ALOS-2), the C-band SAR pixel offset (Sentinel-1), and the optical image pixel offset (Sentinel-2). SAR pixel offset tracking based on SAR amplitude images, also referred to as incoherent speckle tracking, can provide unambiguous surface displacement in both the line of sight (LOS) and azimuth directions by cross-correlating intensities [11-13]. The accuracy can reach $1 / 10$ of one single-look pixel, which indicates its dependency on data pixel size [14,15]. Optical based offset tracking can measure ground deformation with a subpixel accuracy [16] in cloudless areas regardless of displacement gradient. Observations from these methods have been individually used for earthquake modelling [17-19], but few studies have considered combining them all for joint modelling due to their different satellite geometries, observation accuracies, and a proper weighting strategy.

In this study, the observations above-mentioned are combined using an iterative weighting strategy for a joint earthquake modelling. First, satellite data from Sentinel-1, Sentinel-2, and ALOS-2 PALSAR-2 in both ScanSAR and strip map (SM) mode were collected and processed to map the coseismic deformation field and determine the surface trace of the ruptured fault. With the assumption that the Earth crust model is elastic half-space homogeneous [20], finite-fault slips for the earthquake were then jointly inverted from these satellite images. Coulomb failure stress changes were finally calculated and discussed for the uncertainty of the interaction between the Weitin fault and subduction trenches.

\section{Data and Processing Strategy}

Sentinel is a series of Earth observation missions developed by the Copernicus initiative and operated by the European Space Agency (ESA). The Sentinel missions are operated day and night, providing complete, free, and open-access products through the Copernicus Open Access Hub. As the first of five Sentinel missions, Sentinel-1 performs C-band SAR imaging with a constellation of two satellites, Sentinel-1A and Sentinel-1B, running on the same orbital plane. Since the launch of the first satellite in April 2014, Sentinel-1 can offer repeated wide swath $(\sim 250 \mathrm{~km})$ coverage and acquire imagery globally every six or 12 days regardless of the weather with the mode of Terrain Observation with Progressive Scans (TOPS) [21]. Another mission, the Sentinel-2, aims at providing multi-spectral and high-resolution optical imagery, carrying an optical instrument payload that samples 13 spectral bands: four bands at $10 \mathrm{~m}$, six bands at $20 \mathrm{~m}$, and three bands at $60 \mathrm{~m}$ spatial resolution [22]. With the launch of the first Sentinel-2 satellite in June 2015, the mission can offer systematic global coverage of land surfaces with an orbital swath width of $290 \mathrm{~km}$ and a high revisit frequency (e.g., five days at the Equator) [23].

As shown in Table 1, the Sentinel-1 image pair we used in this study was captured on 13 May 2019 and 25 May 2019 from descending track 16. The interferogram was mosaicked from two consecutive frames to cover a larger spatial extent. Considering the ruptured fault as a left-lateral northwest-striking fault with long-standing motion [24], we discarded the usage of the ascending track of Sentinel-1. GAMMA [25] was used to process SAR images in the single look complex format (level 1). To suppress speckle noise, a $20 \times 4$ multi-looking factor was applied in the range and azimuth. Compared with 
traditional SAR interferometry, processing Sentinel TOPS data requires a much more stringent image registration due to the rotation of antenna during the observation of each burst. The accuracy of coregistration in azimuth should be better than 0.001 of a pixel to avoid phase jumps at the interface between adjacent bursts [26]. To achieve such a high accuracy, an iterative amplitude matching procedure was conducted on the SLC after estimating terrain-induced pixel offsets with precise orbits from ESA and a $30 \mathrm{~m}$ digital elevation model (DEM) from the Shuttle Radar Topography Mission (SRTM) [27]. Once the azimuth offset correction is smaller than 0.02 pixels [28], a spectral diversity method considering interferometric phase in the burst overlap areas was used to further reduce coregistration errors. Upon the completion of high-accuracy coregistration, the conventional two-pass SAR interferometry method was followed. The first step was to simulate the topographic phase with the SRTM DEM, from which the differential interferogram was generated. The second step was to filter the interferogram using adaptive spectral filtering [29] and unwrap it using the minimum cost flow (MCF) method [30].

Table 1. Satellite data used in this study.

\begin{tabular}{ccccc}
\hline Satellite & Flight Direction & Reference Date & Repeat Date & Perpendicular Baseline (m) \\
\hline Sentinel-1 & Descending, right looking & 13 May 2019 & 25 May 2019 & 1.1 \\
Senitnel-2 & Orthogonal looking & 11 May 2019 & 26 May 2019 & - \\
ALOS-2 & Descending, right looking & 12 May 2019 & 23 June 2019 & 114.6 \\
ALOS-2 & Ascending, right looking & 09 March 2019 & 01 June 2019 & 598.9 \\
\hline
\end{tabular}

After the above processing, however, we found that the low coherence in this region made the unwrapping extremely difficult. The coherence loss was mainly caused by the heavy vegetation from tropical rainforests. Considering that the pixel spacing of Sentinel-1 in the range direction is about $2.3 \mathrm{~m}$, it is possible to capture range offsets in the near field with SAR pixel offset tracking. The method will first search for the maximum cross-correlation between master and slave image windows after the high-accuracy coregistration, and then it will calculate the offsets between corresponding pixels. Following the offset tracking module in GAMMA software [31], we used a SLC offset search window of $300 \times 60$ pixels and a cross-correlation function window of $32 \times 32$ pixels. The cross-correlation coherence threshold for the acceptance of offsets was set as 0.1. After the offset tracking, we further used a median filter $(9 \times 9)$ to reduce the noise. Figure 2a shows the Sentinel-1 range offsets, where the red star indicates the epicentral location. Although the offsets were not clean enough and terrain-related residuals still seemed to exist, near-field coseismic deformation could clearly be seen. The maximum surface displacement in the range direction reached $2 \mathrm{~m}$. Another finding was that the ground trace of the ruptured fault, extending over $10 \mathrm{~km}$, could be easily recognized from the offset map.

The pre- and post-earthquake Sentinel-2 images (11 May 2019 and 26 May 2019) we used in the study were relatively cloud-free in the near field. We chose two images in band 8 with a resolution of $10 \mathrm{~m}$ and processed them using the COSI-Corr software package [16]. We used a sliding multi-scale window (initial $64 \times 64$ and final $32 \times 32$ pixels), a step size of four pixels, and four robustness iterations to optimize the masking of noise frequencies [17]. To further reduce noise, we discarded outliers greater than $5 \mathrm{~m}$, detrended the displacement map with a linear ramp estimated from a spatial subset that excluded the area near the rupture, and denoised the results with a non-local means filter [32]. Figure $2 b, c$ show the final displacement map in the north and east direction, respectively, where cloud-covered areas on land are masked. The surface trace of the fault rupture is visible on both maps and is consistent with that displayed in the Sentinel-1 range offset map (Figure 2a). To compare Sentinel- 1 and Sentinel-2 deformation measurements in the same direction, we converted the Sentinel-1 range and azimuth offsets to horizontal displacements with Equation (1). The vertical component was not included in the equation since the fault rupture was mainly controlled by strike-slip motion. As shown in Figure 3a,b, the horizontal deformation map from the Sentinel-1 offsets was noisy due to the added azimuth offsets, but the deformation pattern approximately matched those in the Sentinel-2 
deformation maps (Figure 2b,c). We further compared the deformation on the two profiles (denoted in Figure 3a), as shown in Figure $3 \mathrm{c}-\mathrm{f}$ and found that the dispersion of the Sentinel-2 offsets was higher, indicating a lower precision compared to Sentinel-1.
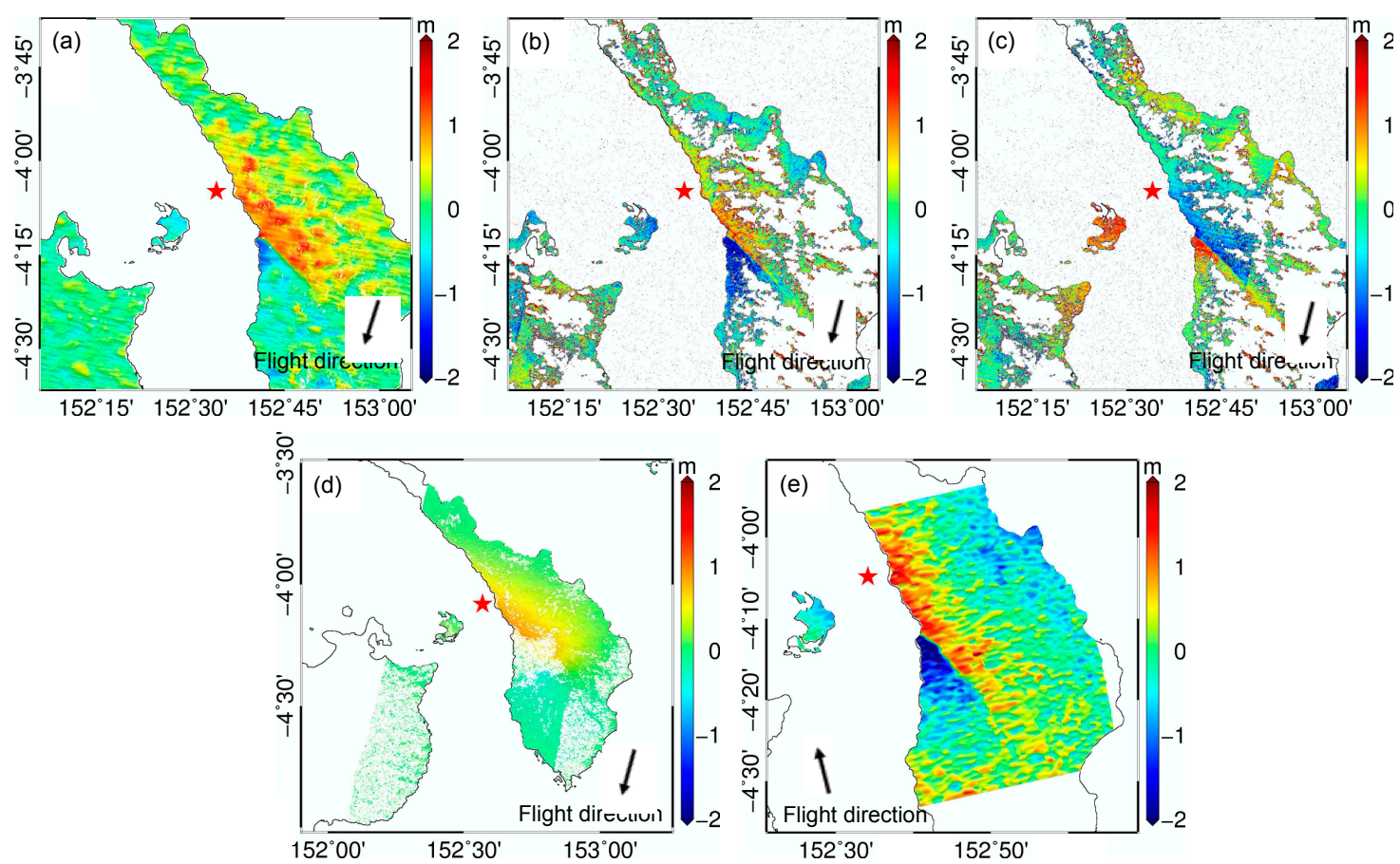

Figure 2. Coseismic displacement maps of the $2019 \mathrm{New}$ Ireland earthquake from Sentinel and ALOS-2 data. (a) Observed offsets in the range direction from descending Sentinel-1 satellite track 16. (b) Observed offsets in the north direction from Sentinel-2 satellite track 116. (c) Observed offsets in the east direction from the same Sentinel-2 images. The on-land areas covered by the cloud are masked in $(\mathbf{b}, \mathbf{c})$. (d) Interferometric synthetic aperture radar (InSAR) deformation in the Line of Sight (LOS) from descending ALOS-2 satellite track 6 (ScanSAR mode). (e) Observed offsets in the azimuth direction from ascending ALOS-2 satellite track 108 (SM mode). The red star denotes the epicentre of this event estimated by USGS.

Inherited from the Advanced Land Observing Satellite (ALOS) in 2014, ALOS-2 carries a phased array type L-band synthetic aperture radar-2 (PALSAR-2) sensor to acquire SAR images. PALSAR-2 has three observation modes: spotlight, strip map (SM), and ScanSAR, where the resolution successively decreases from $3 \mathrm{~m}$ to $100 \mathrm{~m}$ while the observation width increases from $25 \mathrm{~km}$ to $350 \mathrm{~km}$. The revisit time also varies from several months to two weeks, depending on the observation mode and sensing areas. Compared with the C-band wave, the L-band wave can better penetrate vegetation to obtain ground information due to a longer radar wavelength [33], which facilitates the maintenance of coherence in rainforest areas.

According to the data availability for our study area, one descending ALOS-2 image pair from track 6 (12 May 2019 to 23 June 2019) in ScanSAR mode and one ascending image pair from track 108 (09 March 2019 to 01 June 2019) in SM mode were collected and processed. The processing for ALOS-2 ScanSAR images follows the conventional InSAR two-pass method after the mosaic of different swaths. We masked out those decorrelation areas with a coherence threshold of 0.4 to conduct phase unwrapping. The unwrapped displacement map, as shown in Figure 2d, is difficult to completely interpret the coseismic deformation in the near field because of coherence loss. As for those isolated areas such as the island to the southwest of the epicentre, phase unwrapping may not work well due to the lack of effective phase linking. Coherent pixels in the map can still be used in the slip modelling considering the high precision of SAR interferometry. 
The ALOS-2 SM images covering the seismic region is in an ascending track, so the azimuth observations that are almost parallel with the ruptured fault should be visible. We measured the azimuth offsets with the offset tracking module in GAMMA, where the size of the SLC offset search window was set as $128 \times 128$ pixels. The fault trace can also be seen from the ALOS- 2 azimuth offsets (Figure 2e), although within a smaller spatial extent. However, the offsets seem to be noisier than the Sentinel-1 range offsets, especially in the northeast edge, which may be caused by the larger azimuth pixel spacing $(3.8 \mathrm{~m})$ in ALOS-2 SM images.

$$
\left(\begin{array}{c}
\text { East } \\
\text { North }
\end{array}\right)=\left(\begin{array}{cc}
-\cos \alpha \sin \theta & \sin \alpha \sin \theta \\
\sin \alpha & \cos \alpha
\end{array}\right)^{-1}\left(\begin{array}{c}
\text { Range } \\
\text { Azimuth }
\end{array}\right)
$$
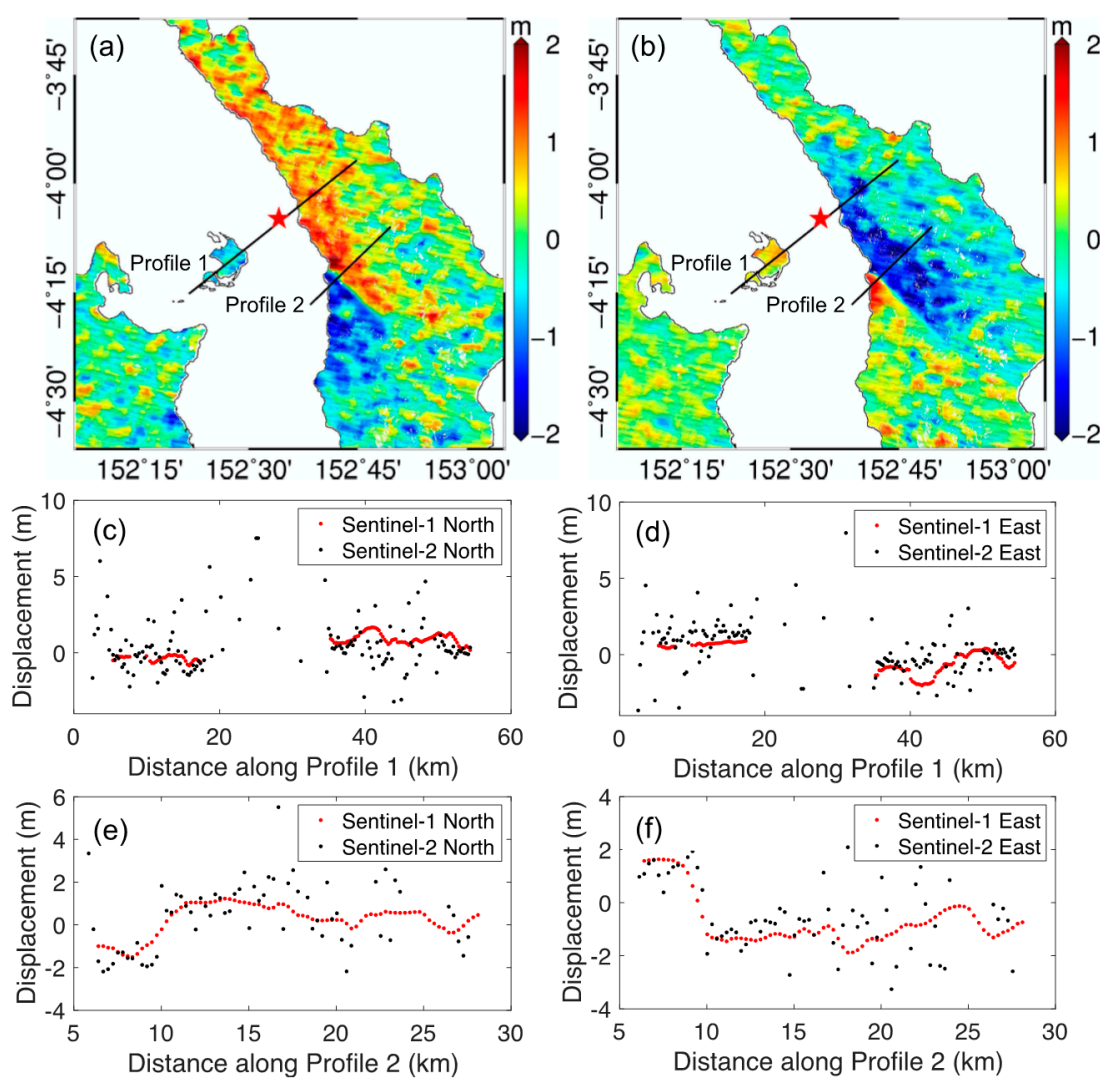

Figure 3. Horizontal deformation of the 2019 New Ireland earthquake decomposed from Sentinel-1 offsets. (a) Coseismic deformation map in the north and (b) east. (c) Coseismic displacement in the north from Sentinel-1 and Sentinel-2 offsets along Profile 1 and (e) Profile 2. (d) Coseismic displacement in the east along Profile 1 and (f) Profile 2.

\section{Geophysical Modelling}

The moment tensor solution from USGS [4] based on teleseismic waveforms suggests two nodal planes. Investigating the deformation patterns from the above images indicates a left-lateral slip component. Therefore, we used a fault plane dipping to the northeast for the inverse of the detailed fault geometry and its slip distribution. According to the Sentinel-1 (Figure 2a), Sentinel-2 (Figure 2b,c), and ALOS-2 (Figure 2e) offset maps, we estimated a surface trace with a strike angle of $315^{\circ}$, which best separates the directions of deformation.

Before inversion, each dataset was subsampled with different downsampling methods. We masked the island in the southwest of the epicentre to avoid possible unwrapping errors and used the quadtree method [34] to downsample the ALOS-2 ScanSAR measurements. For the remaining four offset sets, only pixels around the ruptured fault were extracted to retain a high signal-to-noise 
ratio. We then used the quadtree method to downsample Sentinel-1 and ALOS-2 SM offsets, and applied a subsampling scheme depending on the distance to the fault trace to Sentinel-2 measurements. The sampling interval for pixels within $5 \mathrm{~km}$ was only one, then increased to two for those pixels from $5 \mathrm{~km}$ to $20 \mathrm{~km}$, and finally increased to four for those with a distance farther than $20 \mathrm{~km}$.

\subsection{Inversion Method}

Assuming an elastic homogeneous half-space with a Poisson ratio of 0.25 , a two-step inversion strategy can be used to invert for the fault geometry and the slip distribution. The first step is a nonlinear inversion which estimates the fault geometry by assuming a uniform slip on a rectangular fault plane [35]. The second step is a linear inversion to solve for the finite-fault slip distribution in a least-square sense. In this study, we fixed the strike angle of the fault based on its surface rupture, and then used multipeak particle swarm optimization (M-PSO) with a hybrid minimization algorithm [36] to search for the other fault geometry parameters including the dip angle, the width, length, and depth of the fault plane, and the upper boundary of the ruptured fault. After the determination of the optimal fault geometry, we discretized the fault plane into rectangular sub-patches $(2 \mathrm{~km} \times 2 \mathrm{~km})$. Since the fault dip angle from the uniform model may not be the optimal for spatial-variable slip distribution [37,38], we refined the dip angle based on the relationship between weighted model misfits and multiple dip angles. To limit variations in the slip solution, the Laplacian smoothing was applied with a smoothing factor determined from a trade-off curve between the slip weighted misfit and roughness (as in Figure 4a).
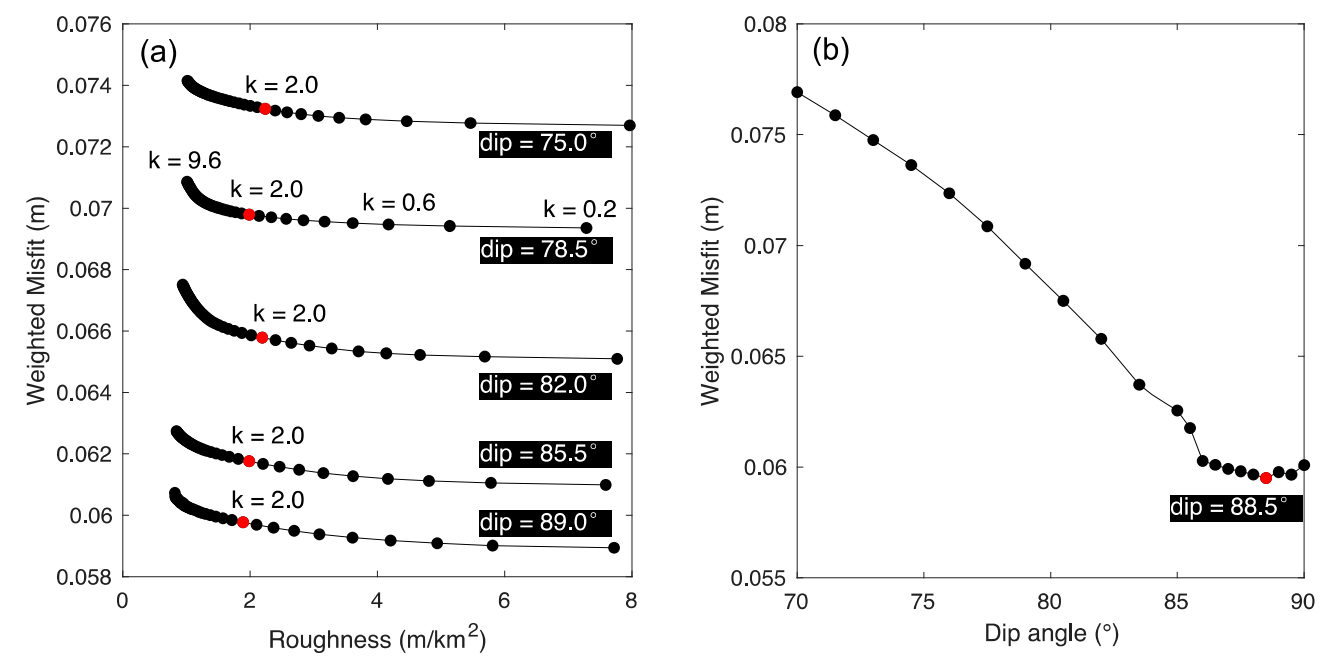

Figure 4. (a) Trade-off curve between the weighted misfit and roughness of the slip model based on different smoothing factors $(\mathrm{k})$, where the solid red circle indicates the preferred smoothing factor used in the joint inversion. (b) The relationship between the weighted misfit of the slip model and the dip angle of the modelled fault. The dip angle corresponding to the minimum model misfit is marked by a red dot.

\subsection{Weighting Strategy}

Following the above inversion strategy, we initially performed individual inversions using each of the five datasets (i.e., ALOS-2 ScanSAR interferometric phases, Sentinel-1 range offsets, ALOS-2 SM azimuth offsets, Sentinel-2 north-south offsets, and Sentinel-2 east-west offsets). The residuals of individual inversion were used to estimate the initial weights of these datasets in the joint inversion, which followed a ratio of 1:0.35:0.16:0.06:0.06. We then used M-PSO to obtain an optimal fault geometry with a length of $68 \mathrm{~km}$, a width of $16 \mathrm{~km}$, a dip angle of $89^{\circ}$, and a strike angle of $315^{\circ}$.

Then, we fixed the fault plane to be $100 \mathrm{~km} \times 20 \mathrm{~km}$ and performed the joint linear inversion. We determined the Laplacian smoothing factor as 2.0, where the fault model fit the observations 
well and exerted a relatively small roughness, regardless of the setting of the dip angles (Figure 4a). We further refined the dip angle to be $88.5^{\circ}$, which corresponded to a least model misfit (Figure $4 \mathrm{~b}$ ). To better balance the contributions of multiple datasets, we iteratively updated the weight ratio using the residual root mean square (RMS) of each dataset. The square of the residual RMS reciprocal was calculated to set the new weight ratio. As shown in Figure 5, after three iterations of joint inversion, the data weight proportion and residual RMS proportion of each dataset tended to be equal, and the final weight ratio was 1:0.14:0.07:0.04:0.05.

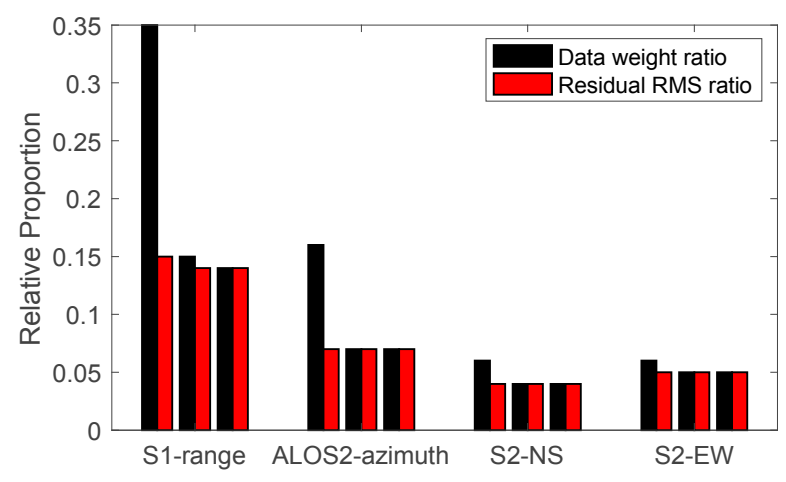

Figure 5. Iterative weighting of each dataset. The relative proportion of data weight and residual root mean square (RMS) of the four datasets is referenced to one that is for the ALOS-2 ScanSAR data. Three groups of bars for each dataset corresponds to three iterations of joint inversion.

\section{Results}

Figure 6 shows the inverted slip distribution on the fault plane from the joint inversion and individual inversion. It can be found that compared to the slip distribution from joint inversion (Figure 6a), the slip distribution inverted from ALOS-2 ScanSAR data only (Figure 6b) can hardly illustrate the onshore surface rupture (12 24 km along strike), while that inverted from the Sentinel-1 (Figure 6c), ALOS-2 SM (Figure 6d), and Sentinel-2 (Figure 6e) offsets seem to overestimate the length of the offshore surface rupture. The checkerboard test was further used to examine the resolution of these slip solutions. We first generated synthetic ground observations based on checkerboard-like slip distributions (Figure 7a), and then inverted them for the slip solution from these synthetic observations using the same inversion method. Results showed that the joint inversion (Figure $7 \mathrm{~b}$ ) retrieved the fault slip slightly better than ALOS-2 ScanSAR only (Figure 7c) in the onshore part (0 31 km along strike), and performed much better than the other three datasets (Figure 7d-f), especially in the offshore part ( $>31 \mathrm{~km}$ along strike). However, the down-dip slip ( $>10 \mathrm{~km}$ along dip) of the offshore region was to some extent underestimated and smeared, since no deformation could be captured on the offshore by satellite sensing.

The results from joint inversion, which offers a comprehensive geophysical interpretation, suggests that the earthquake was mainly controlled by a left-lateral strike-slip component. The maximum strike-slip and dip-slip were $6.07 \mathrm{~m}$ and $0.49 \mathrm{~m}$, respectively, with a rake angle of $4.6^{\circ}$. This preferred model indicates that the fault ruptured to the surface with a length beyond $50 \mathrm{~km}$ and a maximum surface slip of over $5 \mathrm{~m}$. The main slip area extended $18 \mathrm{~km}$ along the down-dip and the peak sliding patches with a slip of $6.10 \mathrm{~m}$ were located at a depth of about $10 \mathrm{~km}$, where the rupture propagated mostly along the strike direction. The estimated geodetic moment (M0) was $1.03 \times 1020 \mathrm{~N} \cdot \mathrm{m}$, corresponding to a magnitude of Mw 7.31.

The predicted displacements from the slip model fit the observations well. The RMS of the misfits were $8.7 \mathrm{~cm}, 23.8 \mathrm{~cm}, 33.8 \mathrm{~cm}, 45.6 \mathrm{~cm}$ and $41.2 \mathrm{~cm}$ for ALOS-2 ScanSAR interferometric phases, Sentinel-1 range offsets, ALOS-2 SM azimuth offsets, Sentinel-2 north-south (NS) offsets and Sentinel-2 east-west (EW) offsets, respectively. We further calculated the model predictions on the ground within each dataset and compared them with original observations. As shown in Figure 8, the deforming 
pattern of models basically followed that of the five datasets, and the residuals in the Sentinel-1 range offset map had the most uniform distribution, although not the smoothest. In the residual map of InSAR data from ALOS-2 ScanSAR (Figure 8c), there were two asperities on the west side of the fault trace, possibly caused by unwrapping errors in the original data. However, the causes of unwrapping errors were different. The island asperity was caused by pixel isolation while the other one is caused by low coherence. The relatively large residuals of ALOS-2 SM and Sentinel-2 (Figure 8i,1,o) were predictable because of their data quality, which is limited by resolution. Another reason for relatively large residuals in the edges of these images is that only the near-field observations were used in the joint inversion. Moreover, the atmospheric artefacts and early post-seismic deformation may also contribute to the residuals.
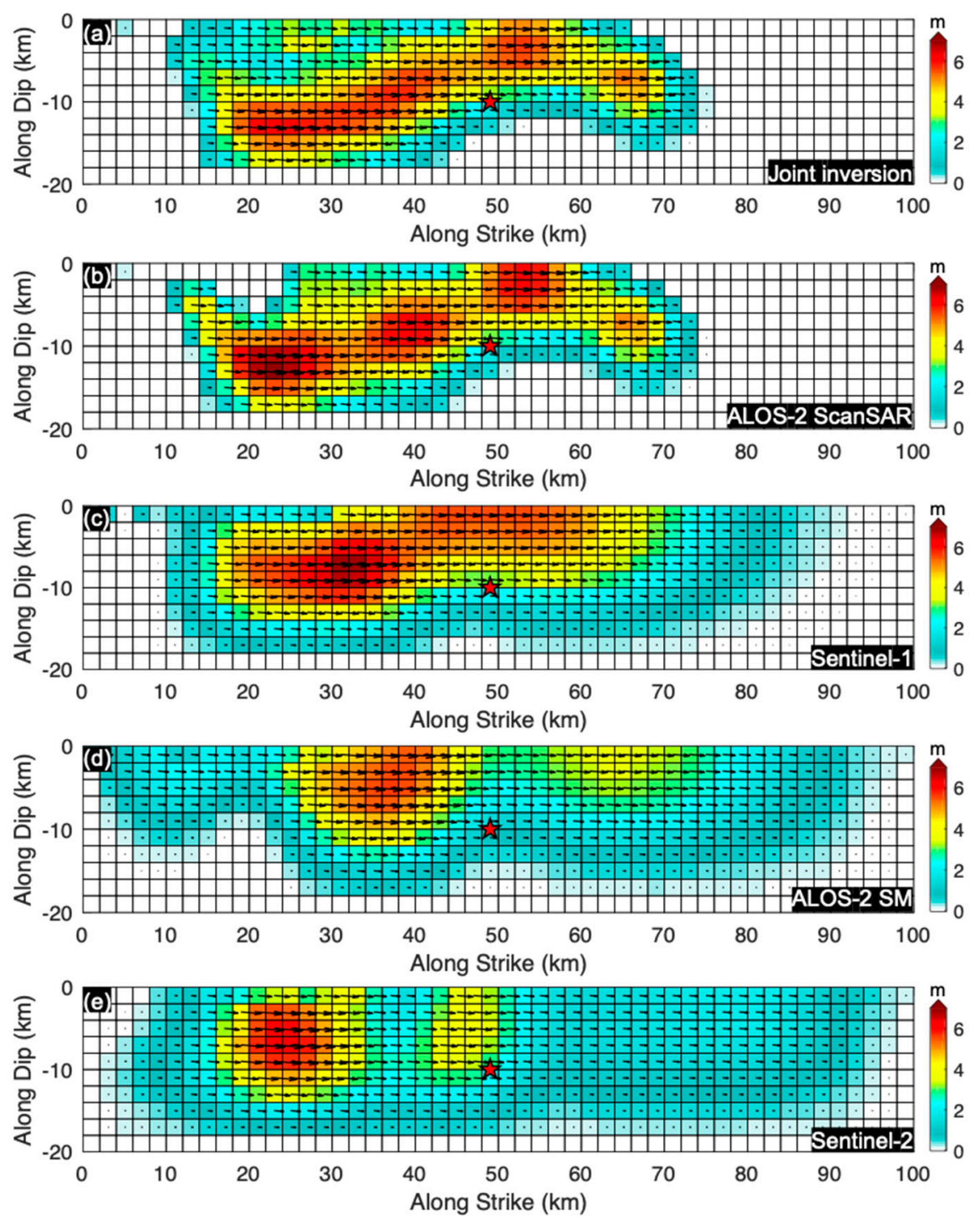

Figure 6. The slip distribution on the fault plane from joint inversion and individual inversion. (a) The slip distribution from joint inversion with the five datasets. (b-e) are the slip distribution from the individual inversion of ALOS-2 ScanSAR interferometric phases, Sentinel-1 range offsets, ALOS-2 SM azimuth offsets, and Sentinel-2 offsets, respectively. The black arrows on the fault patches denote the slip direction. The upper boundary of the fault model corresponds to the surface trace shown in Figure 8 , and the strike direction is from southeast to northwest. The star denotes the source location from the USGS. 

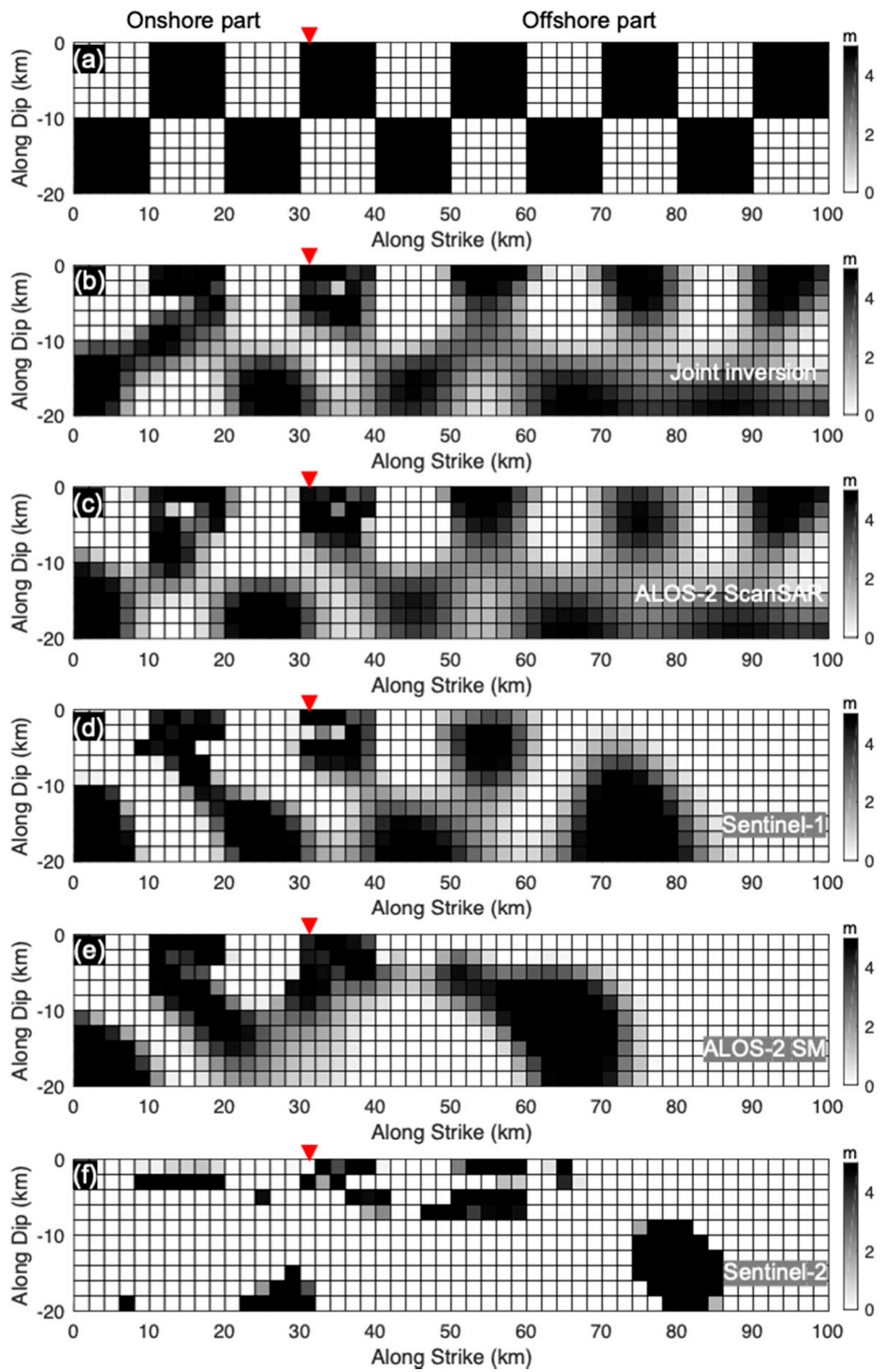

Figure 7. Results of the checkerboard tests. (a) The synthetic slip distribution. (b-f) are the slip solution inverted from the synthetic ground deformation. The downward-pointing triangles denote the location of the intersection of the fault surface trace and coastline. 

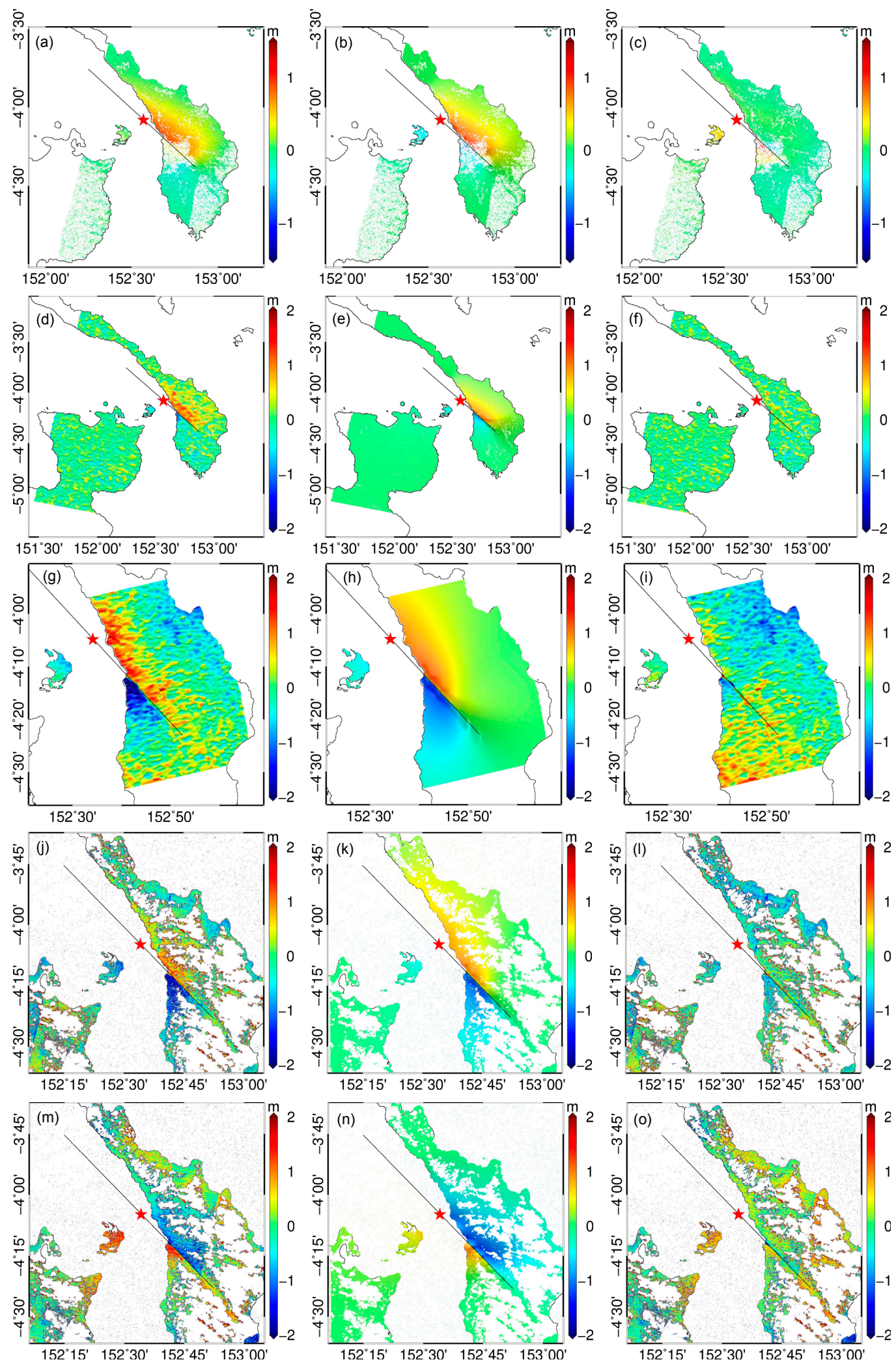

Figure 8. Coseismic satellite observations (left), predictions from our slip model (middle) and residuals between them (right). (a, $\mathbf{d}, \mathbf{g}, \mathbf{j}, \mathbf{m})$ are deformation maps from ALOS-2 ScanSAR interferometry, Sentinel-1 range offsets, ALOS-2 SM azimuth offsets, Sentinel-2 NS, and EW offsets, respectively. The solid black line denotes the surface trace of the ruptured fault, estimated jointly from SAR (Sentinel-1 and ALOS-2) and optical satellite (Sentinel-2) offset maps. 


\section{Discussion}

Due to heavy vegetation in the study area, the C-band SAR interferometry hardly contributes to the mapping of the coseismic deformation field. The L-band ALOS-2 SAR images generate better interferograms, but still suffer coherence loss in areas along the ruptured fault. Such decorrelation may be caused by heavy vegetation or a large deformation gradient. SAR and optical offset fields that can be calculated from Sentinel-1 and Sentinel-2 data are free from coherence loss. Despite the lower precision, offset maps can provide enough near-field data constraints for slip inversion. Moreover, the surface trace of the ruptured fault is consistently displayed in these offset maps, which fixes the strike direction of the fault model. Our study has demonstrated the possibility of combining them for a joint inversion, which is beneficial in areas with limited observations. We also intended to jointly use satellite radar interferograms both in descending and ascending, but the deformation component in the LOS of the ascending ALOS-2/Sentinel-1 interferograms is limited since the strike direction of the ruptured fault conflicts with the satellite azimuth. In addition, there are no ascending ALOS-2 ScanSAR images available spanning the coseismic period.

For joint inversion with multiple data, the determination of the weight of each dataset imposes a large impact on the slip solution. If we ignore the data quality and weight of each dataset equally, a slip distribution with different motion patterns would be generated even with the same fault model and smoothing factor. The relative weight ratio estimated from our iterative weighting method show that the contributions of SAR and optical offsets were lower than $25 \%$. Although our study combined multiple satellite data, most data points were still distributed on one side of the fault, which makes the model constraint unbalanced. The checkerboard test also verified that these satellite data hardly provided good constraints for the offshore slip. This is probably the reason for the lower geodetic moment magnitude.

The slip distribution results indicate a lengthy rupture on the surface. To evaluate the effect of such fault ruptures on the surrounding seismogenic environment, we calculated the Coulomb failure stress (CFS) changes resulting from this event. The CFS changes representing the transfer of stress have been widely used to characterize the evolution of seismicity and quantify the triggering effect of medium/large earthquakes [39-42]. We estimated the CFS on an optimally oriented fault at a depth of $10 \mathrm{~km}$ with a friction coefficient of 0.4. The shear modulus was assumed as $33 \mathrm{GPa}$ for a Poisson's ratio of 0.25 . The aftershocks collected from the USGS were superposed on the map of CFS changes (Figure 9). Although the number of recorded aftershocks were few, most aftershocks $(\sim 70 \%)$ were located in the area with increased CFS. The map also shows that the 2019 New Ireland earthquake increased CFS by more than 5.0 bars along the strike of the ruptured fault, except for the northwest and southeast edges of the faults.

The 16 November $2000 \mathrm{Mw} 8.0$ event shares the same fault structure and initiates from a similar location with this event. Additionally, their aftershocks do not delimit a linear zone of seismicity as expected for near-vertical strike-slip events [5]. However, the aftershocks of the $2000 \mathrm{Mw} 8.0$ event were clustered to the east of the Weitin fault, while those of this event were more scattered around the fault. The shallow rupture of the $2000 \mathrm{Mw} 8.0$ event may have reactivated many older subduction fractures in the upper plate [5], which can explain the static stress changes triggering the two $2000 \mathrm{Mw}$ 7.8 thrust earthquakes [7]. However, in this event, no strong subduction-related activities to the south of the Weitin fault were triggered. We could not deny that the seismicity history repeated on the Weitin fault with a similar rupture mechanism, but the triggering effect of this event was more limited along the plate boundaries and associated structures when compared to the 2000 earthquake sequence, which reflects the uncertainty of the interaction between the Weitin fault and the subduction trenches. 


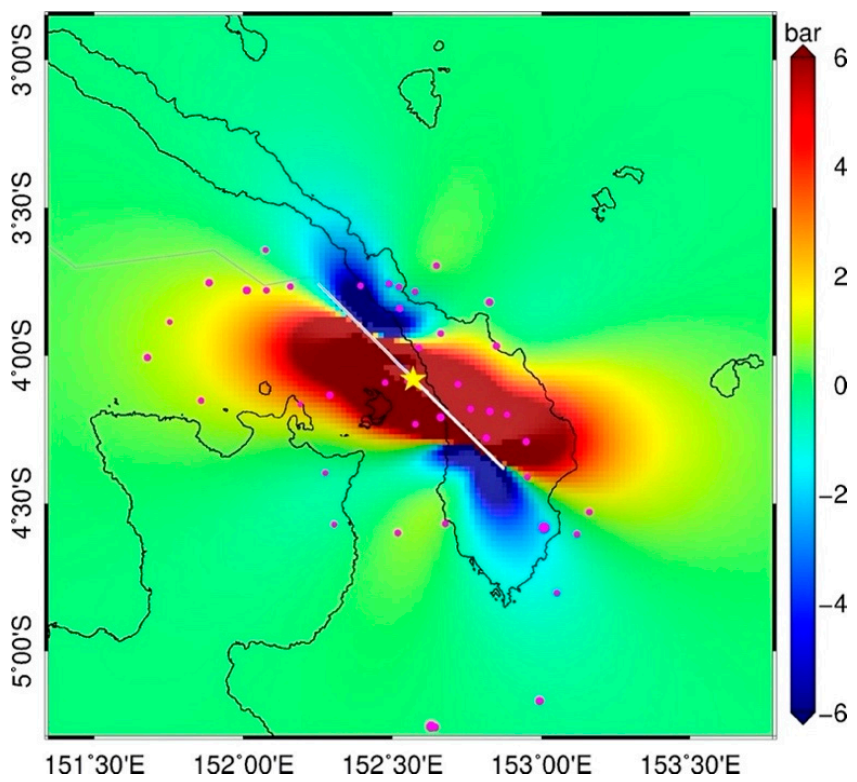

Figure 9. Static Coulomb failure changes due to the 2019 New Ireland earthquake. The yellow star denotes the epicentre. The solid white line is the surface trace of the fault model used in this study. The solid grey line is the offshore extension of the Weitin fault. The magenta dots represent the aftershocks recorded by the USGS.

\section{Conclusions}

In this study, we used multiple remote sensing observations including ALOS-2 ScanSAR interferometric phases, ALOS-2 SM azimuth offsets, Sentinel-1 range offsets, and Sentinel-2 offsets to map the coseismic deformation field and to invert for the slip distribution. First, the surface trace of the ruptured fault was obtained from SAR (Sentinel-1 and ALOS-2 SM) and optical (Sentinel-2) offset fields, which agreed well with each other. Then, an iterative weighting method based on the residual RMS of each dataset was developed to better balance the contributions of multiple datasets, with the Laplacian smoothing factor as 2.0 and the fault dip angle as $88.5^{\circ}$ being successively determined along with the best fitting slip model. The joint inversion technique is beneficial to areas where limited observations are available due to heavy vegetation (e.g., tropical regions) or ice covers (e.g., polar or plateau regions).

The preferred slip distribution suggests a nearly pure left-lateral strike-slip motion on the Weitin fault and a surface rupture length of $\sim 50 \mathrm{~km}$. The maximum slip was $\sim 6.10 \mathrm{~m}$ with a geodetic moment of $1.03 \times 1020 \mathrm{~N} \cdot \mathrm{m}$, corresponding to a magnitude of $\mathrm{Mw} 7.31$. The distribution of aftershocks and Coulomb failure stress changes by this event show that $~ 70 \%$ of aftershocks were located in the area with increased stress and almost no strong aftershocks were triggered in the subduction zone to the south of the Weitin fault.

Author Contributions: C.S. and C.Y. processed the satellite data and performed the result analysis. C.Y. and Z.L. designed the research structure and proposed crucial suggestions for the manuscript. C.S. wrote the manuscript. Y.L. and R.X. provided suggestions on InSAR data processing and reviewed the manuscript.

Funding: This research was funded by the Chinese Scholarship Council studentship awarded to Chuang Song (ref. 201806270247). Part of this work was also supported by the UK Natural Environment Research Council (NERC) through the Centre for the Observation and Modelling of Earthquakes, Volcanoes, and Tectonics (COMET, ref. come30001), the LICS project (ref. NE/K010794/1), the ESA-MOST DRAGON-4 project (ref. 32244), and the National Natural Science Foundation of China (ref. 41704051 and 41804005).

Acknowledgments: The Sentinel-1 and Sentinel-2 data were provided by the European Space Agency (ESA) through Sentinels Scientific Data Hub, and the ALOS-2 PALSAR-2 data were provided by JAXA through the 6th Research Announcement Program for the Advanced Land Observing Satellite-2 (RA-6) (NO.P3051002).

Conflicts of Interest: The authors declare no conflicts of interest. 


\section{References}

1. Holm, R.J.; Rosenbaum, G.; Richards, S.W. Post 8 Ma reconstruction of Papua New Guinea and Solomon Islands: Microplate tectonics in a convergent plate boundary setting. Earth-Sci. Rev. 2016, 156, 66-81. [CrossRef]

2. Llanes, P.; Silver, E.; Day, S.; Hoffman, G. Interactions between a transform fault and arc volcanism in the Bismarck Sea, Papua New Guinea. Geochem. Geophys. Geosyst. 2009, 10, 1-13. [CrossRef]

3. Baldwin, S.L.; Fitzgerald, P.G.; Webb, L.E. Tectonics of the New Guinea Region. Annu. Rev. Earth Planet. Sci. 2012, 40, 495-520. [CrossRef]

4. USGS. Available online: https://earthquake.usgs.gov/earthquakes/eventpage/us70003kyy/executive (accessed on 30 June 2019).

5. Tregoning, P.; Sambridge, M.; McQueen, H.; Toulmin, S.; Nicholson, T. Tectonic interpretation of aftershock relocations in eastern Papua New Guinea using teleseismic data and the arrival pattern method. Geophys. J. Int. 2005, 160, 1103-1111. [CrossRef]

6. Geist, E.L.; Parsons, T. Triggering of tsunamigenic aftershocks from large strike-slip earthquakes: Analysis of the November 2000 New Ireland earthquake sequence. Geochem. Geophys. Geosyst. 2005, 6, 1-18. [CrossRef]

7. Park, S.C.; Mori, J. Triggering of earthquakes during the 2000 Papua New Guinea earthquake sequence. J. Geophys. Res. Solid Earth 2007, 112, B03302.1-B03302.14.

8. Hamling, I.J.; Hreinsdóttir, S.; Clark, K.; Elliott, J.; Liang, C.; Fielding, E.; Litchfield, N.; Villamor, P.; Wallace, L.; Wright, T.J. Complex multifault rupture during the 2016 Mw 7.8 Kaikōura earthquake, New Zealand. Science 2017, 356, 7194. [CrossRef]

9. Massonnet, D.; Rossi, M.; Carmona, C.; Adragna, F.; Peltzer, G.; Feigl, K.; Rabaute, T. The displacement field of the Landers earthquake mapped by radar interferometry. Nature 1993, 364, 138. [CrossRef]

10. Parks, M.M.; Biggs, J.; England, P.; Mather, T.A.; Nomikou, P.; Palamartchouk, K.; Papanikolaou, X.; Paradissis, D.; Parsons, B.; Pyle, D.M. Evolution of Santorini Volcano dominated by episodic and rapid fluxes of melt from depth. Nat. Geosci. 2012, 5, 749. [CrossRef]

11. De Zan, F. Accuracy of incoherent speckle tracking for circular Gaussian signals. IEEE Geosci. Remote Sens. Lett. 2014, 11, 264-267. [CrossRef]

12. Michel, R.; Avouac, J.P.; Taboury, J. Measuring ground displacements from SAR amplitude images: Application to the Landers earthquake. Geophys. Res. Lett. 1999, 26, 875-878. [CrossRef]

13. Wang, T.; Jónsson, S. Improved SAR amplitude image offset measurements for deriving three-dimensional coseismic displacements. IEEE J. Sel. Top. Appl. Earth Obs. Remote Sens. 2015, 8, 3271-3278. [CrossRef]

14. Darvishi, M.; Schlögel, R.; Bruzzone, L.; Cuozzo, G. Integration of PSI, MAI, and Intensity-Based Sub-Pixel Offset Tracking Results for Landslide Monitoring with X-Band Corner Reflectors-Italian Alps (Corvara). Remote Sens. 2018, 10, 409. [CrossRef]

15. Hanssen, R.F. Radar Interferometry: Data Interpretation and Error Analysis; Springer Science \& Business Media: Berlin/Heidelberg, Germany, 2001; Volume 2.

16. Leprince, S.; Barbot, S.; Ayoub, F.; Avouac, J.-P. Automatic and precise orthorectification, coregistration, and subpixel correlation of satellite images, application to ground deformation measurements. IEEE Trans. Geosci. Remote Sens. 2007, 45, 1529-1558. [CrossRef]

17. Socquet, A.; Hollingsworth, J.; Pathier, E.; Bouchon, M. Evidence of supershear during the 2018 magnitude 7.5 Palu earthquake from space geodesy. Nat. Geosci. 2019, 12, 129-199.

18. Wang, S.; Xu, C.; Wen, Y.; Yin, Z.; Jiang, G.; Fang, L. Slip model for the 25 November 2016 Mw 6.6 Aketao earthquake, western China, revealed by Sentinel-1 and ALOS-2 observations. Remote Sens. 2017, 9, 325. [CrossRef]

19. Xu, W.; Feng, G.; Meng, L.; Zhang, A.; Ampuero, J.P.; Bürgmann, R.; Fang, L. Transpressional rupture cascade of the 2016 Mw 7.8 Kaikoura earthquake, New Zealand. J. Geophys. Res. Solid Earth 2018, 123, 2396-2409. [CrossRef]

20. Okada, Y. Surface deformation due to shear and tensile faults in a half-space. Bull. Seismol. Soc. Am. 1985, 75, 1135-1154.

21. Torres, R.; Snoeij, P.; Geudtner, D.; Bibby, D.; Davidson, M.; Attema, E.; Potin, P.; Rommen, B.; Floury, N.; Brown, M. GMES Sentinel-1 mission. Remote Sens. Environ. 2012, 120, 9-24. [CrossRef] 
22. ESA Sentinel Online. Available online: https://sentinel.esa.int/web/sentinel/missions/sentinel-2/overview (accessed on 30 June 2019).

23. Drusch, M.; Del Bello, U.; Carlier, S.; Colin, O.; Fernandez, V.; Gascon, F.; Hoersch, B.; Isola, C.; Laberinti, P.; Martimort, P. Sentinel-2: ESA's optical high-resolution mission for GMES operational services. Remote Sens. Environ. 2012, 120, 25-36. [CrossRef]

24. Tregoning, P.; Jackson, R.J.; McQueen, H.; Lambeck, K.; Stevens, C.; Little, R.P.; Curley, R.; Rosa, R. Motion of the South Bismarck Plate, Papua New Guinea. Geophys. Res. Lett. 1999, 26, 3517-3520. [CrossRef]

25. Werner, C.; Wegmüller, U.; Strozzi, T.; Wiesmann, A. Gamma SAR and interferometric processing software. In Proceedings of the 2000 ERS-Envisat Symposium, Gothenburg, Sweden, 16-20 October 2000; p. 1620.

26. Yagüe-Martínez, N.; Prats-Iraola, P.; Gonzalez, F.R.; Brcic, R.; Shau, R.; Geudtner, D.; Eineder, M.; Bamler, R. Interferometric processing of Sentinel-1 TOPS data. IEEE Trans. Geosci. Remote Sens. 2016, 54, 2220-2234. [CrossRef]

27. Farr, T.G.; Rosen, P.A.; Caro, E.; Crippen, R.; Duren, R.; Hensley, S.; Kobrick, M.; Paller, M.; Rodriguez, E.; Roth, L. The shuttle radar topography mission. Rev. Geophys. 2007, 45, 1-33. [CrossRef]

28. Xu, W. Finite-fault slip model of the 2016 Mw 7.5 Chiloé earthquake, southern Chile, estimated from Sentinel-1 data. Geophys. Res. Lett. 2017, 44, 4774-4780. [CrossRef]

29. Goldstein, R.M.; Werner, C.L. Radar interferogram filtering for geophysical applications. Geophys. Res. Lett. 1998, 25, 4035-4038. [CrossRef]

30. Chen, C.W.; Zebker, H.A. Network approaches to two-dimensional phase unwrapping: Intractability and two new algorithms. JOSA A 2000, 17, 401-414. [CrossRef]

31. Wegnüller, U.; Werner, C.; Strozzi, T.; Wiesmann, A.; Frey, O.; Santoro, M. Sentinel-1 support in the GAMMA software. Procedia Comput. Sci. 2016, 100, 1305-1312. [CrossRef]

32. Buades, A.; Coll, B.; Morel, J.-M. Nonlocal image and movie denoising. Int. J. Comput. Vis. 2008, 76, $123-139$. [CrossRef]

33. Lindsey, E.O.; Natsuaki, R.; Xu, X.; Shimada, M.; Hashimoto, M.; Melgar, D.; Sandwell, D.T. Line-of-sight displacement from ALOS-2 interferometry: Mw 7.8 Gorkha Earthquake and Mw 7.3 aftershock. Geophys. Res. Lett. 2015, 42, 6655-6661. [CrossRef]

34. Jónsson, S.; Zebker, H.; Segall, P.; Amelung, F. Fault slip distribution of the 1999 M w 7.1 Hector Mine, California, earthquake, estimated from satellite radar and GPS measurements. Bull. Seismol. Soc. Am. 2002, 92, 1377-1389. [CrossRef]

35. Feng, W.; Li, Z.; Elliott, J.R.; Fukushima, Y.; Hoey, T.; Singleton, A.; Cook, R.; Xu, Z. The 2011 MW 6.8 Burma earthquake: Fault constraints provided by multiple SAR techniques. Geophys. J. Int. 2013, 195, 650-660. [CrossRef]

36. Feng, W.; Li, Z. A novel hybrid PSO/simplex algorithm for determining earthquake source parameters using InSAR observations. Prog. Geophys. 2010, 25, 1189-1196.

37. Burgmann, R.; Ayhan, M.E.; Fielding, E.J.; Wright, T.J.; McClusky, S.; Aktug, B.; Demir, C.; Lenk, O.; Turkezer, A. Deformation during the 12 November 1999 Duzce, Turkey, earthquake, from GPS and InSAR data. Bull. Seismol. Soc. Am. 2002, 92, 161-171. [CrossRef]

38. Fukahata, Y.; Wright, T.J. A non-linear geodetic data inversion using ABIC for slip distribution on a fault with an unknown dip angle. Geophys. J. Int. 2008, 173, 353-364. [CrossRef]

39. Lin, J.; Stein, R.S. Stress triggering in thrust and subduction earthquakes and stress interaction between the southern San Andreas and nearby thrust and strike-slip faults. J. Geophys. Res. Solid Earth 2004, 109, B03305. [CrossRef]

40. Toda, S.; Stein, R.S.; Richards-Dinger, K.; Bozkurt, S.B. Forecasting the evolution of seismicity in southern California: Animations built on earthquake stress transfer. J. Geophys. Res. Solid Earth 2005, 110, 1-17. [CrossRef] 
41. Xu, C.; Wang, J.; Li, Z.; Drummond, J. Applying the Coulomb failure function with an optimally oriented plane to the $2008 \mathrm{Mw} 7.9$ Wenchuan earthquake triggering. Tectonophysics 2010, 491, 119-126. [CrossRef]

42. Yu, C.; Li, Z.; Chen, J.; Hu, J.-C. Small magnitude co-seismic deformation of the 2017 Mw 6.4 Nyingchi earthquake revealed by InSAR measurements with atmospheric correction. Remote Sens. 2018, 10, 684. [CrossRef]

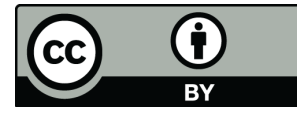

(C) 2019 by the authors. Licensee MDPI, Basel, Switzerland. This article is an open access article distributed under the terms and conditions of the Creative Commons Attribution (CC BY) license (http://creativecommons.org/licenses/by/4.0/). 